\title{
Relationships between the seasonality of temperature and ischaemic heart disease mortality: implications for climate based health forecasting
}

\author{
Glenn R. McGregor ${ }^{1, *}$, Helen A. Watkin ${ }^{2}$, Michelle Cox $^{1}$ \\ ${ }^{1}$ School of Geography, Earth and Environmental Sciences, The University of Birmingham, Birmingham B15 2TT, UK \\ ${ }^{2}$ Met Office, FitzRoy Road, Exeter, Devon EX1 3PB, UK
}

\begin{abstract}
The relationship between the seasonality of ischaemic heart disease (IHD) mortality and temperature is explored for the purpose of evaluating the climate-based predictability of the magnitude and timing of the annual IHD mortality peak for 5 English counties. Seasonality is described by the amplitude (magnitude) and phase (timing) of the first harmonic of the annual cycle of IHD mortality and mean and minimum temperature. Study results reveal a positive association between the amplitude of the annual IHD mortality cycle and temperature seasonality such that years with an exaggerated mortality peak are associated with years characterised by strong temperature seasonality. Overall, the timing of the annual mortality peak is positively associated with the timing of the lowest temperatures. Such findings provide some optimism for exploring the development of experimental climate-based health-forecasting models. This is because the simple climate-seasonality diagnostics presented here provide a fundamental source of predictability of the magnitude and timing of the annual IHD mortality peak.
\end{abstract}

KEY WORDS: Climate and mortality seasonality - Climate-based health forecasting - Seasonal prediction · Ischaemic heart disease mortality

\section{INTRODUCTION}

The British Isles are dominated by high winter climate variability and excess winter mortality. The former is a function of varying interactions between the 3 components of the North Atlantic climate system, namely tropical Atlantic variability, the North Atlantic Oscillation and the Atlantic meridional overturning circulation (Sutton 2000, Marshall et al. 2001) with remote forcing from Pacific Ocean variability also a possibility (Elliot et al. 2001). Despite the complexity of the ocean-atmosphere interactions that influence the inter-annual variability of climate over the British Isles and western Europe, considerable progress has been made in developing both statistical and dynamical seasonal climate prediction models for this region. The purpose of such models is to provide climate information at lead times sufficient to facilitate advanced strategic planning in economic sectors such as agricul- ture, tourism, insurance, energy, retail and transport. However, one sector that has received little consideration, as a potential beneficiary of climate information from seasonal prediction models, is health.

Excess winter mortality in the UK lies between 20000 and 50000 (DoH 2001), which makes the UK one of the most sensitive countries in Europe to winter mortality (Curwen 1991, Eurowinter Group 1997). Furthermore, the inter-annual variability of excess winter mortality appears to be related to winter climate severity (Eurowinter Group 1997). High winter excess mortality is also related to the inability of people, especially the elderly, many of whom live in fuel poverty, to protect themselves against the health effects of cold winters. Clearly, if the UK is to reach parity with its European counterparts, in terms of preventing excess winter mortality and morbidity, then measures are urgently required to reduce the absolute levels of winter deaths and hospitalisations. One way in which 


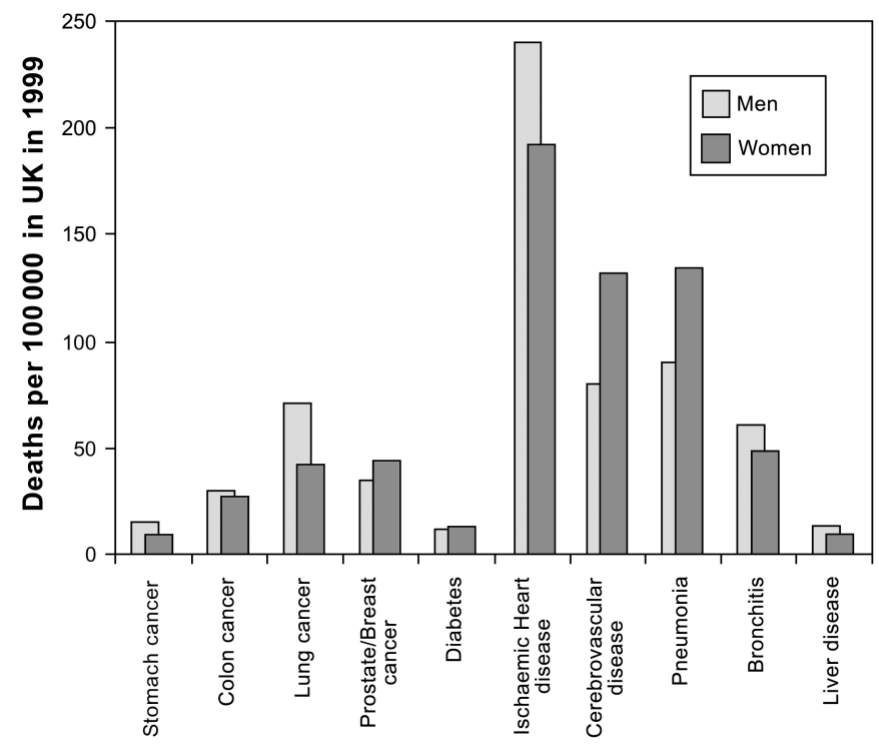

Fig. 1. Leading causes of death in the UK, 1999

this could be achieved is by the provision of climatebased forecasts of the magnitude and timing of the annual mortality peak which occurs in winter. Such health forecasts (HF) could lay the foundations for developing a user-relevant decision support tool to assist the health sector with emergency service and capacity planning and the implementation of intervention strategies for the mitigation of winter-related mortality and morbidity. Necessarily, an underlying assumption of any climate-based HF models will be that antecedent, current or expected future values of climate variables or diagnostics will provide a fundamental source of predictability for a range of health outcomes.

Of chief concern for the UK are respiratory, cerebrovascular and ischaemic heart disease (IHD; Fig. 1). Apart from their weather sensitivity (McGregor 2001), a characteristic of these diseases is the strong seasonality displayed. For example, strong winter peaks of asthma can be identified in general practitioner episodes, hospital admissions and deaths in England, Malta and areas covered by the European Community Respiratory Health Survey (Fleming et al. 2000, Verlato et al. 2000, Grech et al. 2002). Eccles (2002) and Law et al. (2002) have further noted that acute upper and lower respiratory tract viral infections also display clear winter peaks. Similarly, strong winter peaks of acute myocardial infarction and IHD admissions and mortality have been consistently reported over the last $40 \mathrm{yr}$ in the literature for the UK. In early climate and health work, Rose (1966) found high correlations between the December-June ratio of temperature and the December-June ratio of IHD mortality in England and Wales. He also found that the winter excess mortality varied from 20 to $70 \%$ above the relatively smooth summer mortality. Over the whole range of monthly temperatures a rise in temperature was associated with a fall in mortality, with the strength of the effect diminishing exponentially, suggesting a relationship of cause and effect. More recently, Gemmell et al. (2000), Lawlor et al. (2000), Grech et al. (2001) and van Rossum et al. (2001) have also commented on the strong seasonality of cerebrovascular and ischaemic heart disease.

Given the general sensitivity of death and illness to temperature (West 1973, Bull \& Morton 1975, Auliciems \& Frost 1989, Auliciems \& Skinner 1989, McKee 1990, Frost et al. 1992, Frost 1993, Guest et al. 1999, Laschewski \& Jendritzky 2002), diseases such as IHD may be potentially predictable. The purpose of this paper is therefore to undertake an exploratory analysis of the statistical association between the seasonality of temperature and IHD mortality for 5 English counties as a basis for investigating the potential predictability of the magnitude and timing of the annual IHD mortality peak. Of concern is whether relative changes in temperature seasonality from year to year bring about associated changes in mortality seasonality. Therefore, the working hypothesis of the paper is that the interannual variability of the magnitude and timing of the annual IHD mortality peak and temperature seasonality are associated. Accordingly this paper has the following specific objectives: (1) to consider the extent to which the magnitude and timing of the winter IHD mortality peak is dependent on the amplitude of the annual temperature cycle and the timing of the annually lowest temperatures respectively; and (2) to assess the climate-based predictability of the magnitude and timing of the annual IHD mortality peak.

This study falls within the 'mathematical-statistical' category of empirical human biometeorological studies (Driscoll 1999). It explicitly attempts to quantify the relationship between diagnostic measures of the seasonality of temperature and health. Furthermore, it considers temperature and mortality relationships for 5 counties in order to establish whether temperature and mortality seasonality relationships vary geographically.

IHD is focused on because it displays clear sensitivity to weather (McGregor 1999, 2001) and climate (Eurowinter Group 1997). Frequent exposure to cold causes a rise in IHD risk factors (Lloyd 1991) through increasing blood pressure and viscosity, vasoconstriction, heart rate and angina (Morgan \& Morgan 1997). Consequently, the seasonal variation of IHD mortality is often explained in relation to the climatological occurrence of cold weather in winter (Elwood 1993). Moreover, IHD is the leading cause of death in the UK 
(Fig. 1). It has been estimated to cost the UK economy a total of $£ 10$ billion $\mathrm{yr}^{-1}$, more than double that for any other single disease for which a comparable analysis has been carried out (British Heart Foundation 2000). Production losses from death in those of working age greatly contribute to the overall financial burden, but nearly £2000 million of this total represents costs due to hospitalisation and the health-care system in general. These figures provide strong motivation for exploring IHD and temperature seasonality links, as such links could form the basis for developing empirical climatebased seasonal HF models for warning high risk populations and preparing the UK National Health Service for the effects of high winter-related morbidity and mortality.

The 'mathematical-statistical' approach (Driscoll 1999) adopted in this study is justified on the grounds that temperature-IHD mortality associations can be linked to a plausible cold stress-related biophysical transfer mechanism (Curson 1996). Accordingly, all other things being equal, the seasonality and interannual variation of IHD mortality is assumed to be weather and climate sensitive. This assertion is especially valid in the case of the elderly, as winter fuel poverty makes this sector of the population vulnerable to the health effects of cold weather and cold winters (Gemmell 2001).

This paper is organised in the following way. Data and methods are outlined in the next section. Results are then described including a consideration of the association between temperature and IHD mortality seasonality and an evaluation of the seasonal climatebased predictability of IHD mortality. A discussion of the research findings and their implications for seasonal health forecasting is followed by conclusions in the final section.

\section{DATA AND METHODS}

Seasonal temperature and IHD mortality relationships are described for English counties only, as the requisite data were not available for other parts of the UK. The counties for which data were available lay along a south to north gradient, and were Hampshire (H), West Midlands (WM), Greater Manchester (GM), West Yorkshire (WY) and Tyne and Wear (TW) (Fig. 2). The southern- and northern-most counties are centred on 51 and $55^{\circ} \mathrm{N}$ respectively and all lie within the longitudinal range of 1.5 to $2.5^{\circ} \mathrm{W}$. Daily IHD mortality (International Classification of Diseases classes 410.0-414.9) data, adjusted for changes in disease classification, for 1974-1999 were obtained from the Office of National Statistics (ONS) for each county. All mortality data were age standardised to deaths per

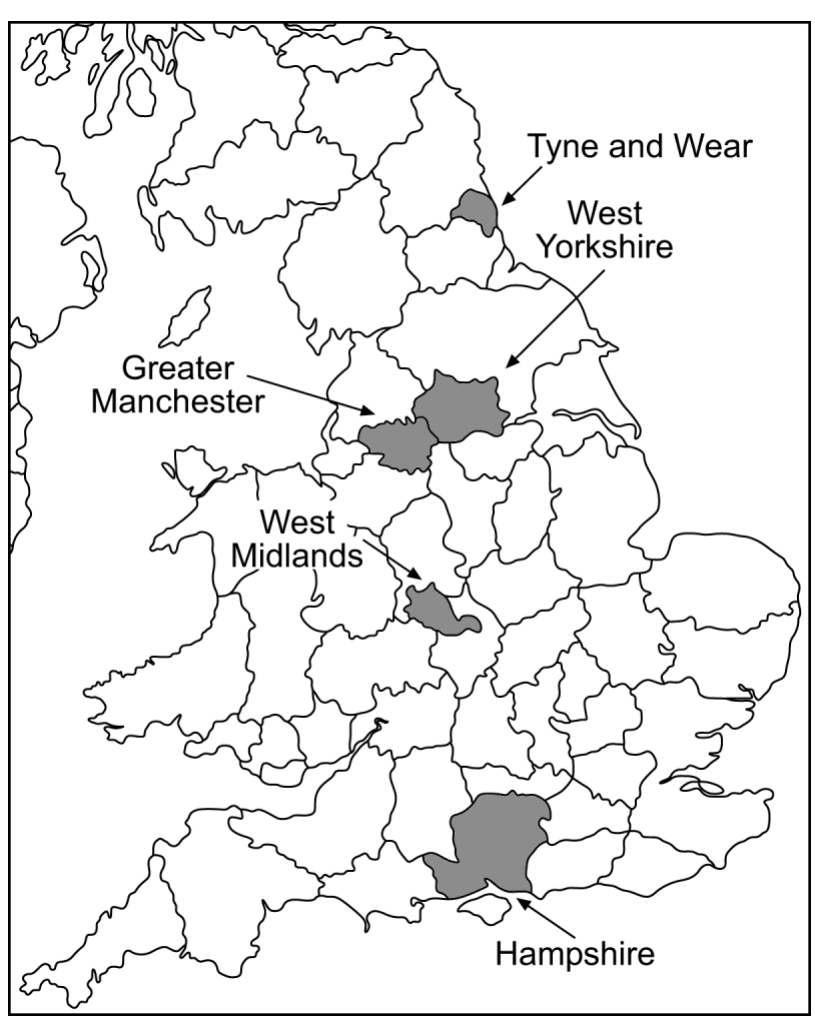

Fig. 2. Location of the 5 counties chosen for study in the UK

100000 using mid-year population estimates, obtained from the ONS. Quality-assured regionally representative daily maximum and minimum temperatures were obtained from the British Atmospheric Data Centre for each of the counties. Maximum and minimum temperatures were used to calculate a mean daily temperature.

The measures used in this paper to describe temperature and IHD mortality seasonality are the magnitude (amplitude) and the timing (phase) of the respective troughs and peaks of the annual cycles of temperature and IHD mortality. These were derived using harmonic analysis (Wilks 1995, Wallace \& Osborn 2002), both for each individual year and for the overall 25 yr climatological average. As IHD mortality and temperature execute a well-defined sinusoidal behaviour over the annual cycle, only the first harmonic was calculated. The first harmonic was calculated for the mean and minimum temperature in order to discover which of these climate diagnostics demonstrated the closest association with the IHD mortality peak. Before harmonic analysis was undertaken the daily data were smoothed with a $5 \mathrm{~d}$ running mean filter so as to remove some of the noise at the daily time scale (Gemmel et al. 2000). This period coincides with the minimum timescale of most mid-latitude weather systems, which are believed to contribute to a considerable por- 
Table 1. Monthly descriptive temperature statistics $\left({ }^{\circ} \mathrm{C}\right)$ for the 5 chosen UK counties arranged from south to north. Mean values are given with maximum and minimum temperatures in parentheses

\begin{tabular}{|lccccc|}
\hline Month & $\begin{array}{c}\text { Hampshire (H) } \\
\left(50^{\circ} 57^{\prime} \mathrm{N}, 1^{\circ} 21^{\prime} \mathrm{W}\right)\end{array}$ & $\begin{array}{c}\text { West Midlands (WM) } \\
\left(52^{\circ} 26^{\prime} \mathrm{N}, 1^{\circ} 45^{\prime} \mathrm{W}\right)\end{array}$ & $\begin{array}{c}\text { Greater Manchester (GM) } \\
\left(53^{\circ} 21^{\prime} \mathrm{N}, 2^{\circ} 16^{\prime} \mathrm{W}\right)\end{array}$ & $\begin{array}{c}\text { West Yorkshire (WY) } \\
\left(53^{\circ} 48^{\prime} \mathrm{N}, 1^{\circ} 32^{\prime} \mathrm{W}\right)\end{array}$ & $\begin{array}{c}\text { Tyne \& Wear (TW) } \\
\left(55^{\circ} 02^{\prime} \mathrm{N}, 1^{\circ} 41^{\prime} \mathrm{W}\right)\end{array}$ \\
\hline 1 & $5.8(7.9,3.6)$ & $3.7(6.4,1.4)$ & $4.3(6.5,2.1)$ & $3.5(6.1,0.9)$ & $4.2(6.2,2.3)$ \\
2 & $5.7(8.1,3.2)$ & $3.8(6.4,1.1)$ & $4.5(7.0,2.0)$ & $3.7(6.2,1.1)$ & $4.7(6.7,2.5)$ \\
3 & $7.6(10.6,4.6)$ & $6.0(9.2,2.9)$ & $6.4(9.3,3.4)$ & $5.6(8.6,2.6)$ & $6.2(8.9,3.6)$ \\
4 & $9.5(13.2,5.7)$ & $7.5(11.8,4.2)$ & $8.3(11.9,4.6)$ & $7.4(10.9,3.9)$ & $7.8(10.9,4.8)$ \\
5 & $12.9(16.9,8.8)$ & $11.1(15.6,6.9)$ & $11.5(15.7,7.4)$ & $10.4(14.6,6.4)$ & $10.4(13.7,7.1)$ \\
6 & $15.6(19.6,11.6)$ & $14.1(18.5,9.9)$ & $14.1(18.0,10.2)$ & $13.2(17.4,9.5)$ & $13.5(16.8,10.1)$ \\
7 & $18.1(22.3,13.9)$ & $16.6(21.0,12.1)$ & $16.4(20.3,12.4)$ & $15.7(19.7,11.8)$ & $15.8(19.3,12.4)$ \\
8 & $17.9(22.0,13.7)$ & $16.1(20.7,11.8)$ & $16.1(20.1,12.1)$ & $15.1(19.5,11.5)$ & $15.7(19.1,12.3)$ \\
9 & $15.4(19.0,11.7)$ & $13.5(17.4,9.6)$ & $13.6(17.0,10.0)$ & $12.8(16.5,9.4)$ & $13.4(16.5,10.1)$ \\
10 & $12.1(15.1,9.1)$ & $10.1(13.4,6.8)$ & $10.4(13.4,7.5)$ & $9.6(12.9,6.5)$ & $10.4(13.0,7.7)$ \\
11 & $8.7(11.2,6.2)$ & $6.7(9.4,3.9)$ & $6.9(9.4,4.6)$ & $6.4(9.1,3.6)$ & $7.1(9.2,5.0)$ \\
12 & $6.7(8.8,4.6)$ & $4.6(7.1,2.1)$ & $5.0(7.1,2.9)$ & $4.4(6.9,1.9)$ & $5.2(6.9,3.4)$ \\
Annual & $11.4(14.6,8.1)$ & $9.5(13.1,6.1)$ & $9.8(13.0,6.6)$ & $9.0(12.4,5.8)$ & $9.6(12.3,6.8)$ \\
\hline
\end{tabular}

tion of the daily variability in IHD mortality in the UK (McGregor 2001). Smoothing at longer timescales was avoided in order to guard against some of the hazards of smoothing, namely the displacement of peaks and troughs in a time series when a filter with a large number of smoothing terms is applied (Davis 1973). A dayof-the-week adjustment of the mortality data was not undertaken, as mortality variations at the seasonal, not the daily, level are of interest to this study. Furthermore, day-of-the-week effects were found to be constant throughout the year and thus are unlikely to affect the magnitude and timing of the mortality peak.

The amplitude of the annual temperature cycle (half the annual range) is taken as a measure of seasonality. The timing of the annual IHD mortality peak and annually lowest temperatures is described by the phase of the first harmonic. Harmonic analysis was chosen to describe annual temperature and mortality peak amplitude and phase characteristics, as opposed to more conventional climatological measures, such as range and the date of the lowest temperature (highest mortality), because harmonic analysis yields precise information about the phase and amplitude in a time series with a well-defined seasonal cycle. Therefore, such measures can be utilised for diagnostic studies of the dynamic relationships between the amplitude and phase of 2 time series.

Relationships between temperature and mortality phase and amplitude are explored using Pearson product moment correlation and linear regression analyses. Temperature and mortality data are normally distributed and therefore meet the requirements of these parametric statistical techniques. A significance level of 0.05 or better is taken as indicative of a statistically significant association between the variables considered in this study.

\section{RESULTS}

\subsection{Temperature characteristics of study locations}

Monthly descriptive temperature statistics for the 5 counties considered in this study are presented in Table 1. On an annual basis, mean maximum temperature decreases northwards. However, the minimum temperature pattern is more complex, with Greater Manchester and Tyne and Wear possessing higher values than the West Midlands. This, in turn, also influences the mean temperature pattern. Perhaps the largest south-to-north anomaly is that for Tyne and Wear: in the winter and autumn months, mean temperature is higher than for its southern counterparts, apart from Hampshire. This reflects Tyne and Wear's maritime location; West Midlands, Greater Manchester and West Yorkshire may be considered to be 'continental' in comparison.

\subsection{IHD mortality and temperature seasonality}

Before analyses of the association between IHD mortality and temperature seasonality were undertaken, time series of mortality peak amplitude and phase, as well as temperature amplitude and phase, were regressed against time in order to test for statistically significant trends over the $25 \mathrm{yr}$ study period. These revealed statistically significant declines in the amplitude of the IHD mortality peak and a forward shift in the timing of peak mortality over the period 1974/75-1998/99. For temperature seasonality, significant trends were only found for the phase of West Midlands minimum temperature and West Yorkshire mean temperature and mean and minimum temperature 
Table 2. Statistically significant trends ( 0.05 level or better) over the 25 yr study period in mortality and temperature seasonality. $\mathrm{r}^{2}$ is squared correlation coefficient, $\mathrm{b}$ is regression coefficient expressed as days per year for phase and deaths per 100000 for amplitude. $p$ is significance level. See Table 1 for county abbreviations

\begin{tabular}{|lccc|}
\hline Variable & $\mathrm{r}^{2}$ & $\mathrm{~b}$ & $\mathrm{p}$ \\
\hline (a) Phase & & & \\
H mortality & 0.48 & -1.287 & 0.01 \\
WM mortality & 0.42 & -1.267 & 0.01 \\
WM minimum temperature & 0.26 & -0.413 & 0.02 \\
GM mortality & 0.33 & -1.074 & 0.01 \\
WY mortality & 0.33 & -1.071 & 0.01 \\
WY mean temperature & 0.22 & -0.395 & 0.02 \\
(b) Amplitude & & & \\
HM mortality & 0.37 & -0.002 & 0.01 \\
GM mortality & 0.25 & -0.002 & 0.01 \\
WY mortality & 0.53 & -0.003 & 0.01 \\
TW mortality & 0.56 & -0.003 & 0.01 \\
TW mean temperature $\left({ }^{\circ} \mathrm{C} \mathrm{yr}^{-1}\right)$ & 0.17 & -0.035 & 0.04 \\
TW minimum temperature $\left({ }^{\circ}{\left.\mathrm{C} \mathrm{yr}^{-1}\right)}^{-1}\right) .17$ & -0.038 & 0.04 \\
\hline
\end{tabular}

amplitude for Tyne and Wear (Table 2). Accordingly, all time series that were found to possess a statistically significant temporal trend were de-trended. Such detrending is considered particularly important in the case of the mortality peak amplitude and phase time series, as this potentially removes from the analysis non-climatic confounders resulting from possible medical-technological improvements over the study period. De-trending was achieved by linear regression modelling with time as the independent variable. Regression-model residuals were added to the mean mortality for the study period to produce a de-trended time series.

Fig. 3 demonstrates the 25 yr climatological relationship between the seasonal cycles of IHD mortality and temperature for all counties as described by the first harmonic, such that the seasonal cycles of temperature and mortality are inversely related. The first harmonic accounts for at least $85 \%$ (significant at the 0.01 level) of the variance of temperature and mortality at both the climatological and yearly time scales. Descriptive statistics of temperature and mortality amplitude and phase are given in Table 3. Although the amplitude of temperature demonstrates a marginal decrease northward, while mortality amplitude increases northward, there is no statistical association between these trends. The timing (phase) of the IHD mortality peak also exhibits no discernable meridional trend. However, for the 2 southern-most counties (Hampshire and West Midlands), the lowest seasonal temperatures precede the mortality peak, while for the remaining northern counties, temperature and mortality phase are coincidental. Comparatively, mortality phase demonstrates a greater variability than that for temperature (Table 3).

As the relationship between the seasonality of temperature and mortality may provide a basis for developing seasonal prediction models of the magnitude
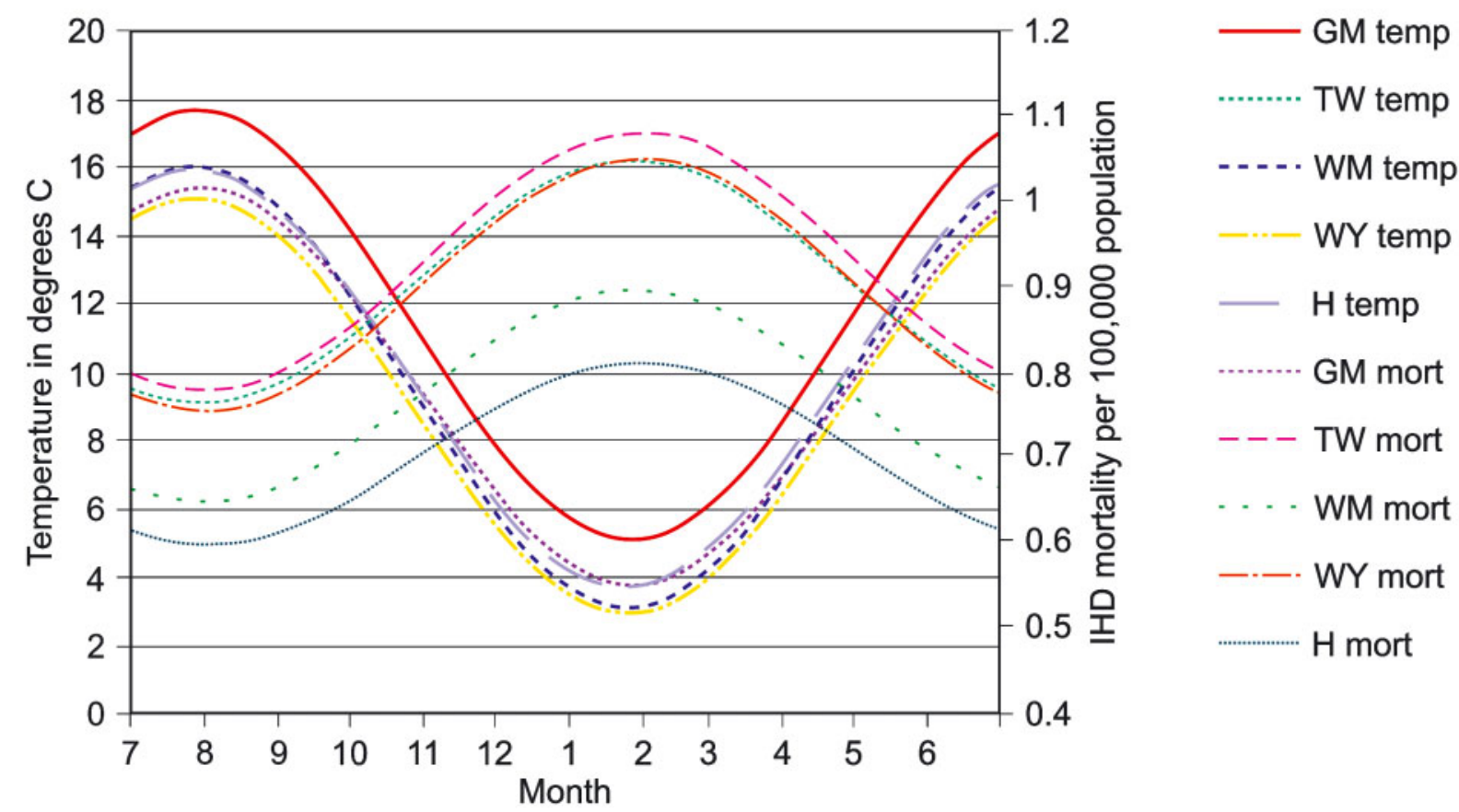

Fig. 3. The 25 yr climatological relationship between the annual cycle of ischaemic heart disease (IHD) mortality (mort) and mean temperature (temp) 
Table 3. Amplitude and phase of mean (SD) temperature $\left({ }^{\circ} \mathrm{C}\right)$ and IHD mortality (deaths per 100 000). Phase is in days from July 1 and is for the lowest mean temperature and highest mortality

\begin{tabular}{|c|c|c|}
\hline County & $\begin{array}{c}\text { Amplitude } \\
\text { Temperature Mortality }\end{array}$ & $\begin{array}{c}\text { Phase } \\
\text { Temperature Mortality }\end{array}$ \\
\hline Hampshire & $6.34(0.71) \quad 0.104(0.031)$ & 209.9 (5.4) 211.4 (13.5) \\
\hline West Midlands & $6.52(0.82) \quad 0.123(0.025)$ & 208.7 (5.5) 210.1 (14.3) \\
\hline Manchester & $6.12(0.76) \quad 0.143(0.027)$ & $207.6(5.4) \quad 207.6(13.7)$ \\
\hline West Yorkshire & $6.10(0.96) \quad 0.146(0.035)$ & $208.0(6.1) \quad 208.3$ (13.6) \\
\hline Tyne and Wear & $5.85(0.67) 0.150(0.038)$ & 210.8 (5.6) $210.4(14.7)$ \\
\hline
\end{tabular}

Table 4. Squared correlations between mean (minimum) temperature and IHD mortality amplitude and phase $(n=25 \mathrm{yr})$. Significance: ${ }^{*} 0.05$ and ${ }^{* *} 0.01$ levels

\begin{tabular}{|lll|}
\hline County & Amplitude & Phase \\
\hline Hampshire & $0.18^{*}\left(0.18^{*}\right)$ & $0.01(0.01)$ \\
West Midlands & $0.31^{*}\left(0.27^{*}\right)$ & $0.07(0.11)$ \\
Manchester & $0.15^{*}\left(0.23^{*}\right)$ & $0.04(0.01)$ \\
West Yorkshire & $0.28^{*}\left(0.43^{* *}\right)$ & $0.31^{*}\left(0.21^{*}\right)$ \\
Tyne and Wear & $0.08(0.11)$ & $0.07(0.07)$ \\
\hline
\end{tabular}

and timing of the IHD mortality peak, of interest is the degree of association between temperature and mortality amplitude and phase statistics. Statistically significant positive associations between the amplitude of temperature and mortality exist for 4 of the 5 counties (Table 4); the amplitude of the mean (minimum) temperature is able to explain between 15 (18) and 31 (43) \% of the variation in mortality amplitude. In contrast, only 1 county demonstrates an association between timing of the annually lowest temperature and the mortality peak, such that the later the occurrence of seasonally lowest mean temperatures, the later the mortality peak (Table 4).

Although the outcome of simple correlation analysis indicates potential climate-based predictability of the IHD mortality peak magnitude and phase, any empirical model built on such statistical associations assumes stationarity. Fig. 4, which presents 10 yr running correlation coefficients from 1974/75-1989/90 and the same for a 5 yr running period beyond that, is an attempt to assess the stationarity of the temperature and mortality seasonality relationship. Although Table 4 indicates statistically significant associations at the overall level for 4 of the counties, it is clear that the strength of the association between temperature and mortality amplitude has varied over the $25 \mathrm{yr}$ study period (Fig. 4). From Fig. 4 it is also clear that some of the counties demonstrate covariant behaviour in their mean (minimum) temperature and mortality relationships, namely Greater Manchester and West Yorkshire $[\mathrm{r}=0.81$
$(0.87), p=0.01]_{i}$ and West Midlands and Hampshire $[r=0.68(0.74), p=0.01]$. Such geographical associations reflect proximity of the counties such that the 2 northern and 2 southern counties appear to be independent of each other. For West Yorkshire and Greater Manchester, and to a lesser extent West Midlands, temperature-mortality associations are statistically significant for 1976/77-1986/87. For Hampshire, the degree of association is generally weak but this demonstrates a statistically significant strengthening trend $(r=0.66 ; \mathrm{p}=0.01)$ up to a correlation peak around 1987/88. Most notable is the rapid deterioration of the asso-
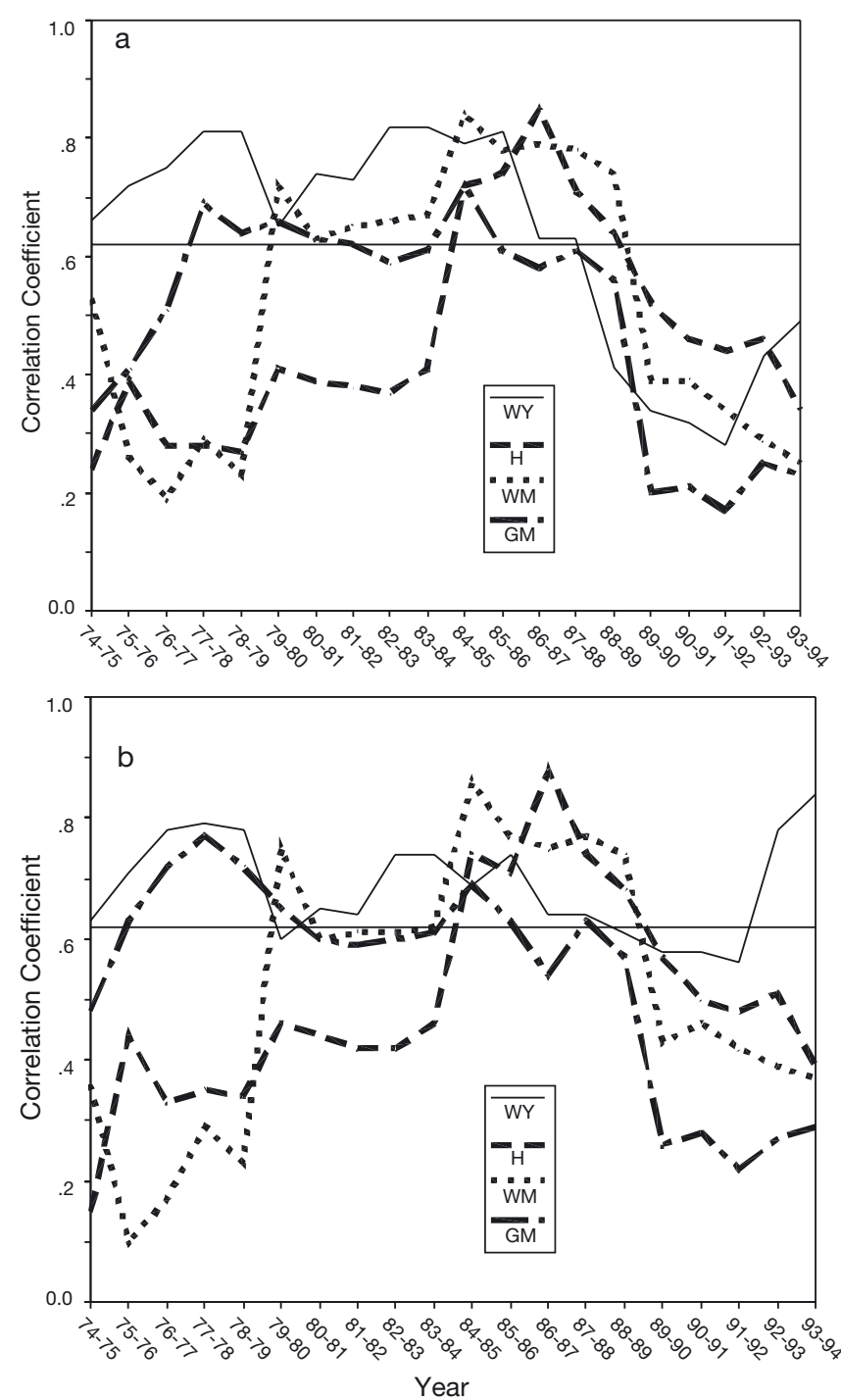

Fig. 4. Running correlation coefficient of the association between (a) mean and (b) minimum temperature and IHD mortality amplitude over the duration of the study period 
ciation between temperature and mortality amplitude beyond approximately 1987/88, apart from the case of West Yorkshire minimum temperature-mortality associations, which are sustained at a significant level over the study period. If the original non-detrended time series is considered then it would appear that the period that defines the divergence in the temperature and mortality association corresponds to the time when both mortality and temperature amplitudes switched to below-average levels, that is, the amplitudes of the annual temperature and mortality cycles were less than the 25 yr climatological value. This is clearly seen in the case of West Yorkshire (Fig. 5) as around $1985 / 86$ to $1986 / 87$ both temperature and mortality amplitudes switch to a below-average mode, such that the study period appears to be characterised by an earlier (later) period when temperature-mortality associations were robust (diminished).

\subsection{Prediction of magnitude and timing of IHD mortality peak}

Despite the time-varying strength of temperature and mortality seasonality associations, the above analyses indicate that mortality seasonality demonstrates some sensitivity to variations in the temperature seasonality. Such associations may lay the basis for the development of climate-based HF models. The purpose of this section is therefore to present an exploratory analysis of the predictability of the magnitude and timing of the annual IHD mortality peak for West Yorkshire as this county demonstrates the most sustainable temperature-mortality relationship of the 5 counties considered. The approach adopted is based around regression analysis with IHD mortality amplitude and phase as the predictand. Mean and minimum temperature amplitude and phase are used as the predictors. Firstly, IHD amplitude (phase) was predicted as a function of temperature amplitude and phase separately using simple linear regression analysis. Multiple stepwise regression analysis was then used to develop models that predict mortality amplitude (phase) as a function of both temperature amplitude and phase; stepwise regression analysis was used to establish the relative explanatory power of the 2 predictors.

The results from regression analyses of IHD mortality amplitude and phase on temperature amplitude and phase for West Yorkshire are presented in Table 5. These can be considered as specification regression models as they attempt to characterise variations in IHD seasonality using concurrent variations in temperature seasonality. No results are shown for the multiple stepwise regression analyses as the combined effects

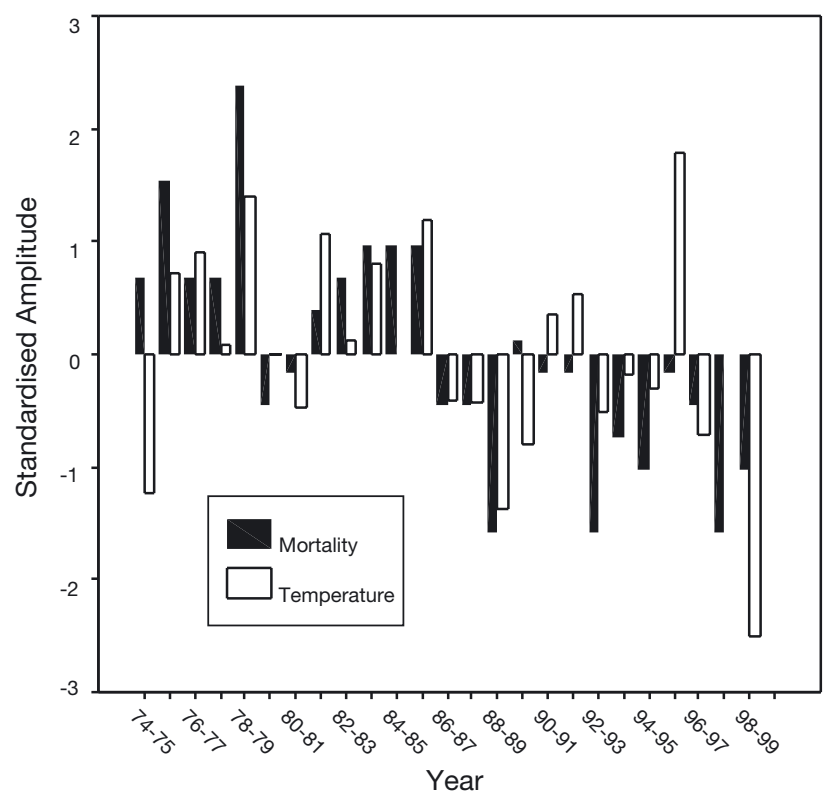

Fig. 5. Inter-annual variability of temperature and IHD mortality amplitude. Note the trend to below-average amplitude post 1986/87

of temperature phase and amplitude were found to make no significant contribution to the explanation of IHD amplitude and phase variance respectively. While the output from specification models is useful for understanding the nature of the predictor-predictand relationship and for possible application in climate change impact assessments, notwithstanding the assumption of stationarity, future values of the forecast variables are required to validate specification models. As such, the specification models presented in Table 5

Table 5. Regression analysis of IHD amplitude and phase on temperature seasonality diagnostics for all years $(n=25)$ for West Yorkshire. $r^{2}$ is coefficient of determination, $p$ is level of significance. Two sets of regressions are shown; (a) and (b) are for amplitude and phase predictors only. No regression models are shown for combined predictors (temperature phase and amplitude) of IHD amplitude or phase, as such models are the same as in (a) and (b) respectively, that is, phase (amplitude) contributed insignificantly to the prediction of amplitude (phase). Mean and min refer to mean and minimum temperature respectively

\begin{tabular}{|llcc|}
\hline \multirow{2}{*}{ Predictand } & Predictors & $\mathrm{r}^{2}$ & $\mathrm{p}$ \\
\hline (a) IHD amplitude & Temperature amplitude only & \\
& $\begin{array}{l}0.022 \text { min amplitude } \\
\text {-0.016 constant }\end{array}$ & 0.43 & 0.01 \\
(b) IHD phase & Temperature phase only & & \\
& 0.898 mean phase & & \\
& 1.15 constant & 0.31 & 0.01 \\
& & & \\
\hline
\end{tabular}


reveal little about the predictability of IHD mortality seasonality. To this end, quasi-cross-validation of a set of regression models was undertaken such that 3 models for each predictand (IHD amplitude and phase) were 'trained' and 'tested' on 3 independent 20 and $5 \mathrm{yr}$ periods respectively. The training (test) periods were the winters of 1979/80-1998/99 (1974/751978/79); 1974/75-1993/94 (1994/95-1998/99); and 1974/75-1983/84 and 1989/90-1998/99 (1984/851988/89). Regression models developed for the 3 training periods are referred to as Models 1, 2 and 3 respectively. The training periods were chosen as they span periods typified by a mixture of strong-to-poor (Model 1), predominantly strong (Model 2) and strongand-improving (Model 3) temperature-mortality relationships. Likewise, the 3 test periods are characterised by strong (Model 1), improving (Model 2) and poor (Model 3) temperature-mortality seasonality relationships.

Evaluation of the $\mathrm{r}^{2}$ predicted versus observed statistics in Table 6 reveals varying degrees of model predictability for both diagnostics of the annual IHD mortality peak. Of the 3 mortality amplitude models presented in Table 6, Model 1a has the highest predicted versus observed $r^{2}$. This is perhaps to be expected as Model 1a was trained on a period with strong-to-poor and improving temperature-mortality associations, but tested on a period with strong such relationships. The results for mortality peak amplitude Model 3a are encouraging, as this model was trained on a period with strong and improving temperature-mortality relationships, but tested on a period with poor such relationships, indicating that this model is fairly robust. For mortality peak phase,
Model $2 \mathrm{~b}$ produces the greatest predictability but this remains inferior to that achieved by the 2 best amplitude models (Models 1a and 3a). No results are shown for the IHD amplitude and phase prediction models based on combining temperature amplitude and phase, as these provided no noteworthy improvement over the models that only utilise amplitude as the predictor.

\section{DISCUSSION}

Evaluation of the trend of mortality seasonality characteristics revealed significant decreases in the amplitude of the annual IHD mortality peak and a forward shift of its timing for most of the 5 counties. For Hampshire, West Midlands, Greater Manchester and West Yorkshire, the decrease in mortality peak amplitude occurs in the absence of significant changes in temperature seasonality. This may indicate possible desensitisation, of the study populations, to the relative effects of temperature seasonality on mortality seasonality. This corroborates the findings for other countries such as Germany (Lerchl 1998), Japan (Honda 2000), Scotland (Gemmel et al. 2000), and the United States (Seretakis 1997), where declines in mortality seasonality have been noted. A likely explanation for this is improvement in the nature of housing stock, the increased use and availability of home heating and improving health systems (Keatinge et al. 1989, Lerchl 1997, Aylin et al. 2001). As noted by Davis et al. (2002) such 'technological improvements' have resulted in the general climate de-sensitisation of US urban populations.

Table 6. Regression models of IHD amplitude and phase. Models 1, 2 and 3 have different model development and test periods (see text). The explanation for regression sets (a) and (b) is the same as for Table $5 . \mathrm{r}^{2}$ pred vs obs: percentage variance of the observed values accounted for by the predicted values $(\mathrm{n}=5)$; significance: ${ }^{*} 0.05$ level

\begin{tabular}{|c|c|c|c|c|}
\hline Predictand & Predictors & $r^{2}$ & $\mathrm{p}$ & $\mathrm{r}_{\text {pred vs obs }}^{2}$ \\
\hline (a) IHD amplitude & Mean and min temperature amplitude only & & & \\
\hline Model 1a & $\begin{array}{l}0.019 \text { min amplitude } \\
\text {-0.002 constant }\end{array}$ & 0.32 & 0.01 & $0.73^{*}$ \\
\hline Model 2a & $\begin{array}{l}0.024 \text { mean amplitude } \\
-0.045 \text { constant }\end{array}$ & 0.51 & 0.01 & 0.243 \\
\hline Model 3a & $\begin{array}{l}0.018 \text { min amplitude } \\
0.010 \text { constant }\end{array}$ & 0.28 & 0.01 & $0.71^{*}$ \\
\hline (b) IHD phase & Mean and min temperature phase only & & & \\
\hline Model 1b & $\begin{array}{l}0.943 \text { mean phase } \\
-7.82 \text { constant }\end{array}$ & 0.35 & 0.01 & 0.08 \\
\hline Model 2b & $\begin{array}{l}0.845 \text { mean phase } \\
0.112 \text { constant }\end{array}$ & 0.22 & 0.01 & 0.62 \\
\hline Model 3b & $\begin{array}{l}0.978 \text { mean phase } \\
-15.19 \text { constant }\end{array}$ & 0.37 & 0.01 & 0.07 \\
\hline
\end{tabular}


Although the observation of climate desensitisation of populations is relatively new, of particular interest is the discovery, in this study, of a forward shift of the timing of the annual mortality peak over the $25 \mathrm{yr}$ study period. For 2 of the 5 counties (West Midlands and West Yorkshire) this shift occurs in parallel with significant changes in the timing of the seasonally lowest temperatures (Table 2), which suggests a possible cause and effect relationship. To investigate this, the degree to which the trend in mortality peak timing can be attributed to the trend in temperature phase was evaluated. Using the original non de-trended time series, attribution was established by regressing mortality peak phase on temperature and then finding the product of the resultant regression coefficient and the temperature trend (Tuomenvirta et al. 2000). For West Midlands and West Yorkshire a large proportion of the forward shift in mortality peak phase can be attributed to parallel trends in temperature, especially the timing of the annually lowest mean temperature for the West Midlands and the minimum temperature for West Yorkshire (Table 7). For the other counties changes in the timing of the lowest temperatures appear to play a smaller role in accounting for the forward shift of the mortality peak.

The fact that a forward displacement of the winter mortality peak is possibly climate driven is supported by the findings of Wallace \& Osborn (2002), who have shown that there has been a phase advance of minimum temperature for Northern Hemisphere land areas over the twentieth century. Similarly, the climate and phenology community have also noted phenological changes for some plant, vertebrate and invertebrate communities due to a foreshortening of winter as a consequence of autumn and spring occurring later and earlier respectively (Sparks \& Menzels 2002). However, the accreditation of the idea that phase advances of IHD mortality are driven by the earlier occurrence of annually low temperatures will have to await the proof of an association between annual mortality peak onset/cessation criteria and timing (phase) of the annually lowest temperatures.

Table 7. Attribution (days $\mathrm{yr}^{-1}$ ) of mean and minimum temperature trend to trend in mortality peak phase (see Table 2). Negative values indicate forward shift in time

\begin{tabular}{|lccc|}
\hline County & $\begin{array}{c}\text { Trend in } \\
\text { phase }\end{array}$ & $\begin{array}{c}\text { Mean } \\
\text { temperature }\end{array}$ & $\begin{array}{c}\text { Min } \\
\text { temperature }\end{array}$ \\
\hline Hampshire & -1.29 & -0.14 & -0.13 \\
West Midlands & -1.27 & -0.52 & -0.36 \\
Greater Manchester & -1.07 & -0.22 & -0.21 \\
West Yorkshire & -1.07 & -0.48 & -0.62 \\
Tyne and Wear & -0.75 & -0.28 & -0.29 \\
\hline
\end{tabular}

Furthermore, conceivably, changes in timing and indeed amplitude of the IHD mortality peak may be associated with climate and health changes in summer.

De-trended measures of temperature and IHD mortality seasonality have been shown to possess sympathetic but inverse associations at both the climatological and inter-annual timescales. Generally, the seasonality of IHD mortality peak is dependent on the seasonality of temperature. Furthermore, there is some evidence that the timing of the annual mortality peak is dependent on the same for the annually lowest temperatures. Comparatively, the relative effects of temperature amplitude on mortality peak amplitude are greater than the effect of the timing of the lowest temperatures on the timing of the mortality peak. This is because the phase of temperature and IHD mortality appears to be coincident in some years but not in others. In years when the lowest temperatures occur earlier than the climatological norm, the mortality peak is coincident with the timing of the lowest temperatures. However, in years when the lowest temperatures occur later than usual, the IHD mortality peak occurs near the norm; the temperature-mortality phase relationship breaks down in such years. This may be attributable to 2 main factors. Firstly, as the peak of the winter coldness is later, by this stage the pool of susceptible individuals may have been drastically reduced by the health effects of periods of cold weather earlier in the winter prior to the winter mortality peak, hence the mortality peak is brought forward in time. Secondly, short-term acclimatisation of any remaining susceptible individuals may also moderate the impacts of cold on IHD mortality later in the winter season. Therefore, despite the occurrence of low temperatures, there is not a matching mortality response. Although intraseasonal acclimatisation and mortality displacement (Kalkstein \& Davis 1989, McMichaels et al. 1996, McGregor 1999) may account for the observed divergence in the timing of the seasonally highest mortality and lowest temperatures, substantiation of these factors requires an analysis of intra-seasonal climate and mortality diagnostics. A further factor that may complicate the relationship between winter climate and IHD mortality is the occurrence of influenza. This is considered important in elevating winter mortality above that of summer and also contributing to the inter-annual variability of winter mortality levels (Eurowinter Group 1997). Furthermore, deaths attributable to IHD may in fact be the result of influenza (Simonsen et al. 2001). If so, the isolation of the winter climate signal from that of influenza and other co-morbid factors will be difficult and likely to pose problems for the climate-based prediction of general winter mortality levels, especially for years with severe influenza epidemics. 


\section{CONCLUSIONS}

That the level of winter IHD mortality may be potentially predictable is supported by the fact that simple diagnostics of mortality seasonality exhibit statistically significant associations with similar measures of temperature seasonality. However, the strength of these associations vary geographically such that the temperature-mortality seasonality relationship appears to be strongest for the most 'continental' counties. Exploratory cross validation of 3 mortality peak amplitude and mortality peak timing prediction models for one county has produced encouraging results. This is despite the partial instability of seasonal temperaturemortality relationships. Although mean seasonal temperature data could have been used to construct the experimental seasonal HF models presented in this study, such models would not deliver information on the timing of the annual mortality peak. For this reason it is suggested that models based upon diagnostics of seasonality, such as amplitude and phase, will provide greater utility for winter emergency service planning, which has an important magnitude and timing component in terms of the work load of the emergency services and when peak demand for such services is likely to occur.

Although study findings provide some optimism for exploring the development of experimental climatebased HF models, little research has been undertaken to establish whether current climate prediction technology, using coupled climate models, can deliver the requisite information for climate-based intra-seasonal to seasonal HF models. Therefore, there is a need to evaluate current climate prediction products in terms of their ability to support health-sector-related decision-making. Furthermore, from an operational point of view, the problems that have been found elsewhere to restrict the successful assimilation of climate information into decision-support systems for agriculture, water resources and fisheries (Nicholls 1999, Goddard et al. 2001) need to be evaluated for the health sector given the potential stakeholder status of this sector in climate-prediction science.

As coupled-climate-model technology, and thus the predictability of climate, will improve over the next decade, there is an urgent need to assess what aspects of intra-seasonal to seasonal climate are potentially predictable and how associated future climate products could be built into future decision support systems for the health sector. This is because the overlap between current and future climate forecast products, and the spectrum of user needs within the health sector, will define the direction of future research on experimental climate-based health-forecasting models and products. Therefore, there is an immediate need to gather knowledge concerning the nature of winter climate and health links at current and likely future climate forecast time scales and assess how such information could be assimilated into climate-informed decision-support tools for emergency service and capacity planning within the UK health sector. This represents a challenging research issue for the climate-prediction applications and health-research communities and will also provide considerable added value for climate-change health-impact studies.

Acknowledgements. Part of this work was completed under the UK Natural Environment Research Council's 'Coupled Ocean and Atmospheric Processes and European Climate (COAPEC): Bridging the Gap Between Science and Society' programme grant NER/T/S/2002/00155. Comments from 3 anonymous reviewers and guidance from the editor have led to a much improved paper.

\section{LITERATURE CITED}

Auliciems A, Frost DB (1989) Temperature and cardiovascular deaths in Montreal. Int J Biometeorol 33:151-156

Auliciems A, Skinner JL (1989) Cardio-vascular deaths and temperature in subtropical Brisbane. Int J Biometeorol 33: 215-221

Aylin P, Morris S, Wakefield J, Grossinho A, Jarup L, Elliott P (2001) Temperature, housing, deprivation and their relationship to excess winter mortality in Great Britain, 1986-1996. Int J Epidemiol 30:1100-1108

British Heart Foundation (2000) Coronary heart disease statistics: British Heart Foundation Statistics Database 2000. British Heart Foundation, Oxford

Bull GM, Morton J (1975) Environment temperature and death rates. Age Ageing 7:210-224

Curson P (1996) Human health, climate and climate change: an Australian perspective. In: Giambelluca T, HendersonSellers A (eds) Climate. J Wiley and Sons, Chichester

Curwen M (1991) Excess winter mortality: a British phenomenon? Health Trends 1990 22:169-175

Davis JC (1973) Statistics and data analysis in geology. John Wiley \& Sons, New York

Davis RE, Knappenberger PC, Novicoff WM, Michaels PJ (2002) Decadal changes in heat-related human mortality in the eastern United States. Clim Res 22:175-184

DoH (2001) Health effects of climate change in the UK: an expert review for comment. UK Department of Health, London

Driscoll D (1999) Some directions for human biometeorology in the new century. In: de Dear RJ, Potter JC (eds) Proceedings of the 15th International Congress of Biometeorology and International Conference on Urban Climatology, Sydney Australia, 8-12 November 1999. Paper ICB4.2, CD-ROM, Division of Environmental and Life Sciences, Macquarie University, Sydney

Eccles R (2002) An explanation for the seasonality of acute upper respiratory tract viral infections. Acta Oto-Laryngol 122:183-191

Elliott JR, Jewson SP, Sutton RT (2001) The impact of the 1997/98 El Niño event on the Atlantic Ocean. J Clim 14: 1069-1077

Elwood PC (1993) Temperature and risk factors for ischaemic heart disease in the Caerphilly prospective study. Br Heart J 70:520-525 
Eurowinter Group (1997) Cold exposure and winter mortality from ischaemic heart disease, cerebrovascular disease, respiratory disease and all causes in warm and cold regions of Europe. Lancet 349:1341-1346

Fleming DM, Cross KW, Sunderland R, Ross AM (2000) Comparison of the seasonal patterns of asthma identified in general practitioner episodes, hospital admissions, and deaths. Thorax 55:662-665

Frost DB (1993) Myocardial infarct death: the population at risk and temperature habituation. Int $\mathrm{J}$ Biometeorol 37 : $46-51$

Frost DB, de Freitas C, Auliciems A (1992) Myocardial infarct death and temperature in Auckland, New Zealand. Int J Biometeorol 36:14-17

Gemmell I (2001) Indoor heating, house conditions and health. J Epidemiol Comm Health 55:928-929

Gemmell I, McLoone P, Boddy FA, Dickinson GJ, Watt GCM (2000) Seasonal variations in mortality in Scotland. Int J Epidemiol 29:274-279

Goddard L, Mason SJ, Zebiak S, Ropelewski CF, Basher R, Cane M (2001) Current approaches to seasonal to interannual climate predictions. Int J Climatol 21:1111-1152

Grech V, Aquilina O, Pace J (2001) Gender differences in seasonality of acute myocardial infarction admissions and mortality in a population-based study. J Epidemiol Comm Health 55:147-148

Grech V, Balzan M, Asciak RP, Buhagiar A (2002) Seasonal variations in hospital admissions for asthma in Malta. J Asthma 39:263-268

Guest CS, Wilson K, Woodward AJ, Hennessy K, Kalkstein LS, Skinner C, McMichael AL (1999) Climate and mortality in Australia: retrospective study, 1979-1990, and predicted impacts in five major cities in 2030. Clim Res 13: $1-15$

Honda Y (2000) Shift of the short-term temperature-mortality relationship by a climate factor: some evidence necessary to take account of in estimating the health effect of global warming. J Risk Res 1:209-20

Kalkstein LS, Davis RE (1989) Weather and human mortality: an evaluation of demosgraphic and interregional responses in the United States. Ann Assoc Am Geogr 79:44-64

Keatinge WR, Coleshaw S, Holmes J (1989) Changes in seasonal mortalities with improvement in home heating in England and Wales from 1964 to 1984. Int J Biometeorol 33:71-76

Laschewski G, Jendritzky G (2002) Effects of the thermal environment on human health: an investigation of 30 years of daily mortality data from SW Germany. Clim Res 21:91-103

Law BJ, Carbonell-Estrany X, Simoes EAF (2002) An update on respiratory syncytial virus epidemiology: a developed country perspective. Respir Med Suppl B 96:S1-S7

Lawlor DA, Harvey D, Dews HG (2000) Investigation of the association between excess winter mortality and socioeconomic deprivation. J Pub Health Med 22:176-181

Editorial responsibility: Robert Davis,

Charlottesville, Virginia, USA
Lerchl A (1998) Changes in the seasonality of mortality in Germany from 1946 to 1995: the role of temperature. Int J Biometeorol 42:84-88

Lloyd EL (1991) The role of cold in ischaemic heart disease: a review. Pub Health 105:205-215

Marshall RT, Kushnir Y, Battisti D, Chang, P, Czaja A, Dickson R, Hurrell J, McCartney M, Saravanan R, Visbeck M (2001) North Atlantic climate variability: phenomena, impacts and mechanisms. Int J Climatol 21:1863-1898

McGregor GR (1999) Winter ischaemic heart disease deaths in Birmingham, UK: a synoptic climatological analysis. Clim Res 13:17-31

McGregor GR (2001) The meteorological sensitivity of ischaemic heart disease mortality events in Birmingham, UK. Int J Biometeorol 45:133-142

McKee CM (1990) Deaths in winter in Northern Ireland: the role of low temperature. Ulster Med J 59:17-22

McMichaels AJ, Haines A, Sloof R, Kovats S (1996) Climate change and human health. World Health Organisation, Geneva

Morgan MD, Moran JM (1997) Weather and people. Prentice Hall, Englewood Cliffs, NJ

Nicholls N (1999) Cognitive illusions, heuristics and climate prediction. Bull Am Meteorol Soc 80:1385-1397

Rose G (1966) Cold weather and ischaemic heart disease. $\mathrm{Br}$ J Prevent Soc Med 20:97-100

Seretakis D, Lagiou P, Lipworth L, Signorello LB, Rothman KJ, Trichopoulos D (1997) Changing seasonality of mortality from coronary heart disease. J Am Med Assoc 278: 1012-1014

Simonsen L, Clarke MJ, Williamson GD, Stroup DF, Arden NH, Schonberger LB (2001) The impact of influenza epidemics on mortality: introducing a severity index. Am J Pub Health 87:1944-1950

Sparks TH, Menzels A (2002) Changes in the timing of the seasons: an overview. Int J Climatol 22:1715-1725

Sutton RT (2000) The elements of climate variability in the tropical Atlantic region. J Clim 13:3261-3284

Tuomenvirta H, Alexandersson H, Drebs A, Frich P, Nordli PO (2000) Trends in Nordic and Arctic Temperature extremes and ranges. J Clim 13:977-990

van Rossum CTM, Shipley MJ, Hemingway H, Grobbee DE, Mackenbach JP, Marmot MG (2001) Seasonal variation in cause-specific mortality: are there high-risk groups? 25-year follow-up of civil servants from the first Whitehall study. Int J Epidemiol 30:1109-1116

Verlato G, Calabrese R, De Marco R (2002) Correlation between asthma and climate in the European Community Respiratory Health Survey. Arch Environ Health 57:48-52

Wallace CJ, Osborn TJ (2002) Recent and future modulation of the annual cycle. Clim Res 22:1-11

West RR (1973) Mortality from ischaemic heart disease: association with weather. Brit J Prevent Soc Med 27:36-40

Wilks D (1995) Statistical methods in the atmospheric sciences. Academic Press, San Diego

Submitted: September 3, 2002; Accepted: October 22, 2003

Proofs received from author(s): December 8, 2003 